\title{
Effects of Upper Airway Anaesthesia on the Hyperdynamic Response to Tracheal Intubation
}

\author{
JAMAL A. AL HASHEMI, MBBS, MSc, FRCPC, FCCP \\ Department of Anesthesia \& Critical Care, Faculty of Medicine \& Allied Sciences \\ King Abdulaziz University, Jeddah, Saudi Arabia
}

\begin{abstract}
Tracheal intubation is associated with a hyperdynamic response characterized by hypertension and tachycardia. Several drugs have been used to attenuate this response; however, anaesthetizing the superior laryngeal nerves of this purpose has not been formally studied. This study was designed to determine the effects of bilateral superior laryngeal nerve block and those of nebulized lidocaine on the hyperdynamic response to tracheal intubation. Forty-six patients were randomized, in a prospective, placebo-controlled, single blind trial, to receive bilateral superior laryngeal nerve block (SLN), nebulized lidocaine (NBL), or no intervention (CON). Blinding was achieved by placing a band-aid on the neck bilaterally all patients. A standard anaesthesia protocol was followed in all patients. Measurements of mean arterial pressure (MAP, systolic blood pressure (SBP), diastolic blood pressure (DBP), and heart rate (HR) were obtained pre-induction, at induction, and every minute for $10 \mathrm{~min}-$ utes after tracheal intubation. Opioids and surgical stimuli were withheld during the study period.

Tracheal intubation resulted in comparable increases in MAP, SBP, DBP, and HR among all patient groups. The maxium increases in these parameters were observed at 1-2 minutes following intubation. Although other haemodynamic variables returned to baseline, all patients continued to be tachycardiac $10 \mathrm{~min}$ utes after airway instrumentation. This study demonstrated that upper airway anaesthesia with either bilateral SLN block or nebulized lidocaine was ineffective by itself in attenuating the hyperdynamic response to tracheal intubation.
\end{abstract}

Keywords: Superior laryngeal nerve block, Nebulized lidocaine, Tracheal intubation, Hypertension, Tachycardia

Correspondence \& reprint requests to: Dr. Jamal A. Alhashemi, Department of Anesthesia \& Critical Care, King Abdulaziz University, P.O. Box 80215, Jeddah 21589, Saudi Arabia. e-mail: jaalhashemi@hotmail.com

Accepted for publication: 05 January 2003. Received: 10 August 2002. 


\section{Introduction}

Tracheal intubation elicits a hyperdynamic response characterized by hypertension and tachycardia in the majority of patients who undergo this form of airway instrumentation $^{[1]}$. Although such a response would likely be tolerated by healthy patients, it might not be tolerated well by those with significant coronary artery or cerebrovascular disease. For this reason, numerous drugs have been used to attenuate the circulatory response to tracheal intubation ${ }^{[2-4]}$. However, the success rate of these drugs have been variable ${ }^{[2]}$, and the long duration of action of some of them has been of concern. Furthermore, there is limitation to the use of certain drugs despite their effectiveness in attenuating the circulatory response to tracheal intubation. An example is beta-adrenergic blocking drugs, which are contraindicated in patients with reactive airway disease, which in turn limits their usefulness in this group of patients.

In contrast to intravenous drugs, upper airway anaesthesia has not been formally studied as a potential modality for blunting this haemodynamic response to tracheal intubation. Since the observed circulatory changes are thought to be somato-visceral reflexes that are triggered during laryngoscopy ${ }^{[5]}$, we hypothesized that anaesthetizing the upper airway would attenuate these reflexes and minimize the accompanying circulatory changes. A prospective, randomly, single blind, placebo-controlled study was, thus, undertaken to determine the effects of bilateral superior laryngeal nerve block and those of nebulized lidocaine on the hyerdynamic response to tracheal intubation.

\section{Methods}

Study Population: After institutional Ethics Board approval, 46 American Society of Anesthesiologists physical class I-II patients, scheduled for elective surgery, gave written informed consent to participate in this randomly, single blind, placebo-controlled study. Subjects were excluded from the trial if they had any of the following: hypertension; coronary artery or cerebrovascular disease; beta-blocker or clonidine therapy; neck mass; upper airway pathology; known or suspected difficulty with tracheal intubation; body weight < $50 \mathrm{~kg}$; gastro-oesophageal reflux; or any contraindication to superior laryngeal nerve block. Based on a computer-generated randomization schedule, patients were randomly placed in one of the three study groups; bilateral superior laryngeal nerve block (SLN), nebulized lidocaine (NBL), or control (CON) group.

Anaesthetic Technique \& Measurements: Midazolam $20 \mu \mathrm{g} \mathrm{kg} \mathrm{kg}^{-1} \mathrm{IV}$ was administered to all patients upon arrival to the operating room. Baseline measurements of the patient's mean arterial pressure (MAP), systolic blood pressure (SBP), diastolic blood pressure (DBP), and heart rate (HR) were obtained non-invasively using Danamap® (Critikon, Tampa FL). In group SLN patients, a 27-gauge, 1" - long needle attached to a $3 \mathrm{ml}$-syringe was walked off the inferior border of the greater cornu of the hyoid bone near its tip. Three millilitres of $2 \%$ lidocaine was then infiltrated both superficially and deep to the thyrohyoid membrane at this site ${ }^{[6]}$. The same procedure was then repeated on the other side. In contrast, subjects in group NBL had their upper 
airway anaesthetized with $5 \mathrm{ml}$ of $4 \%$ lidocaine administered over 10 minutes by nebulizer with $\mathrm{O}_{2}$ flow set at $10 \mathrm{~L} / \mathrm{min}$; whereas, group CON patients had no intervention. Therapeutic interventions prior to induction of anaesthesia were performed by the authors, who were not involved with the care of the patients in the operating room. The anaesthetist caring for the patients was blinded by placing a non-transparent band-aid over the greater conru of the hyoid bone, bilaterally, in all study patients. Haemodynamic data were automatically recorded and printed out using the Dinamap's ${ }^{\circledR}$ built-in printer, and were entered into the study database by a blinded person.

Anaesthesia was induced within 5 min of performing upper airway anaesthesia in the intervention groups, and within the same time frame after administering midazolam to the control group. Following pre-oxygenation, the Dinamap® was activated to record MAP, SBP, DBP, and HR on induction, and every minute for 10 minutes after tracheal intubation. All patients received $d$-tubocurarine $0.05 \mathrm{mg} \mathrm{kg}^{-1} \mathrm{IV}$, followed by propofol $2.5 \mathrm{mg} \mathrm{kg}^{-1} \mathrm{IV}$, and succinylcholine $2 \mathrm{mg} \mathrm{kg}^{-1} \mathrm{IV}$. Tracheal intubation was performed, by a consultant anaesthetist blinded to the patient's study group, one minute after succinylcholine administration using a McIntosh-type blade. Anaesthesia was maintained with $1 \%$ inspired isoflurane, $70 \% \mathrm{~N}_{2} \mathrm{O}$, and $30 \% \mathrm{O}_{2}$, at a fresh gas flow of $4 \mathrm{~L} / \mathrm{min}$. Haemodynamic data were recorded for 10 minutes after intubation, during which time surgical stimuli and the administration of narcotics were withheld. All subjects were extubated awake at the end of the procedure; all intraoperative and postoperative adverse effects were recorded.

Statistical Analysis: Based on an estimated variance of $(20)^{[2]}$, a power of $90 \%$, and an $a$ of 0.05 , a total 63 patients were required to detect a difference of $20 \mathrm{mmHg}$ in MAP between either of the intervention groups and the control group. The trial, however, was stopped after a preplanned interim analysis, which was performed after enrolling $75 \%$ of the study patients. Post hoc power analysis was performed using an $a$ of 0.05 , sigma of 10.32 (obtained from the computer output of univariate tests), and the observed group means.

Minitab $^{\circledR}$ software package, release 12.23 for Windows ${ }^{\circledR}$ (Minitab Inc., State College, PA), was used for sample size calculation and power analysis. MAP, SBP, DBP, and HR data were analyzed using repeated measures analysis of variance. The analysis was performed using SPSS ${ }^{\circledR} 9.0$ statistical package (SPSS Inc., Chicago, IL) for Windows 95/98. Results are presented, throughout the text, table, and figures, as mean \pm SD and statistical significance was defined as a $P<0.05$.

\section{Results}

Of the 46 study-participants, 16 patients were randomly chosen for SLN group; 15 to NBL; and 15 to CON. Baseline characteristics were similar among the study groups (Table 1). Tracheal intubation resulted in comparable increases in MAP, SBP, and DBP among the study groups, with the maximum elevation in pressure occurring at 1-2 minutes after intubation (Figs. 1-3). The estimated marginal means for MAP were as 
follows: SLN $93 \pm 10 \mathrm{mmHg}$; NBL $93 \pm 11 \mathrm{mmHg}$; and CON $90 \pm 10 \mathrm{mmHg}$. The 95\% confidence intervals for the differences in MAP among the various study groups were as follows: SLN-NBL (-8.3, 7.0); SLN-CON (-4.6, 10.2); and NBL-CON (-4.5, 11.3). Similarly, the $95 \%$ confidence intervals for the differences in SBP were SLNNBL $(-12.9,8.0)$; SLN-CON $(-5.6,14.4)$; and NBL-CON $(-3.9,17.6)$; and those for DBP were SLN-NBL (-6.4, 6.1); SLN-CON (-4.4, 7.7); and NBL-CON (-4.6, 8.3). There was no difference in the magnitude of HR increase following tracheal intubation amongst the three patient groups (Fig. 4) [95\% confidence interval for the differences amongst the groups: SLN-NBL (-8.6, 7.4); SLN-CON $(9.4,5.9)$; and NBL-CON (-9.5, 7.2)]. In contrast to other haemodynamic parameters, HR remained elevated at $10 \mathrm{~min}-$ utes after tracheal intubation in all study patients (Fig. 4). There were no study-related complications amongst all patients.

TABLE 1. Patient's characteristics

\begin{tabular}{|c|c|c|c|}
\hline Group & $\begin{array}{c}\text { SLN } \\
(n=16)\end{array}$ & $\begin{array}{c}\text { NBL } \\
(n=15)\end{array}$ & $\begin{array}{c}\text { PLA } \\
(n=15)\end{array}$ \\
\hline Age $(y r)$ & $41.8 \pm 8.9$ & $37.9 \pm 8.0$ & $34.7 \pm 7.3$ \\
\hline Weight $(k g)$ & $75.1 \pm 13.7$ & $78.4 \pm 21.4$ & $68.1 \pm 15.9$ \\
\hline Height $(\mathrm{cm})$ & $168.2 \pm 10.8$ & $169.6 \pm 9.8$ & $166.3 \pm 9.9$ \\
\hline Gender $(M / F)$ & $6 / 10$ & $8 / 7$ & $4 / 11$ \\
\hline ASA class $(I / I I)$ & $14 / 2$ & $11 / 4$ & $14 / 1$ \\
\hline
\end{tabular}

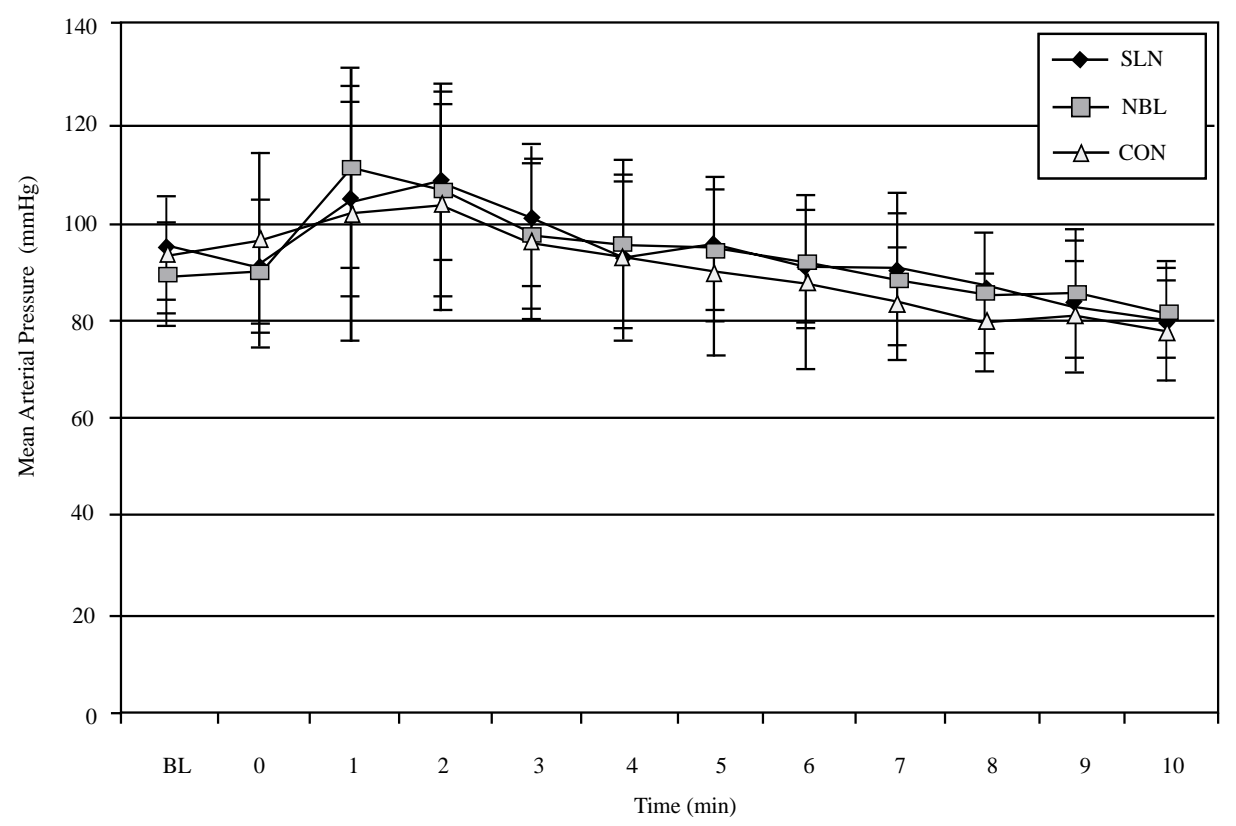

Fig. 1 Changes in mean arterial pressure over Time.

Data points indicate group $\pm \mathrm{SD}$.

$B L=$ Baseline $; 0=$ Induction $; N=$ Minute $(s)$ after intubation $; S L N=$ Superior laryngeal nerve block $; B L=$ Nebulized lidocaine $; P L A=$ Placebo 


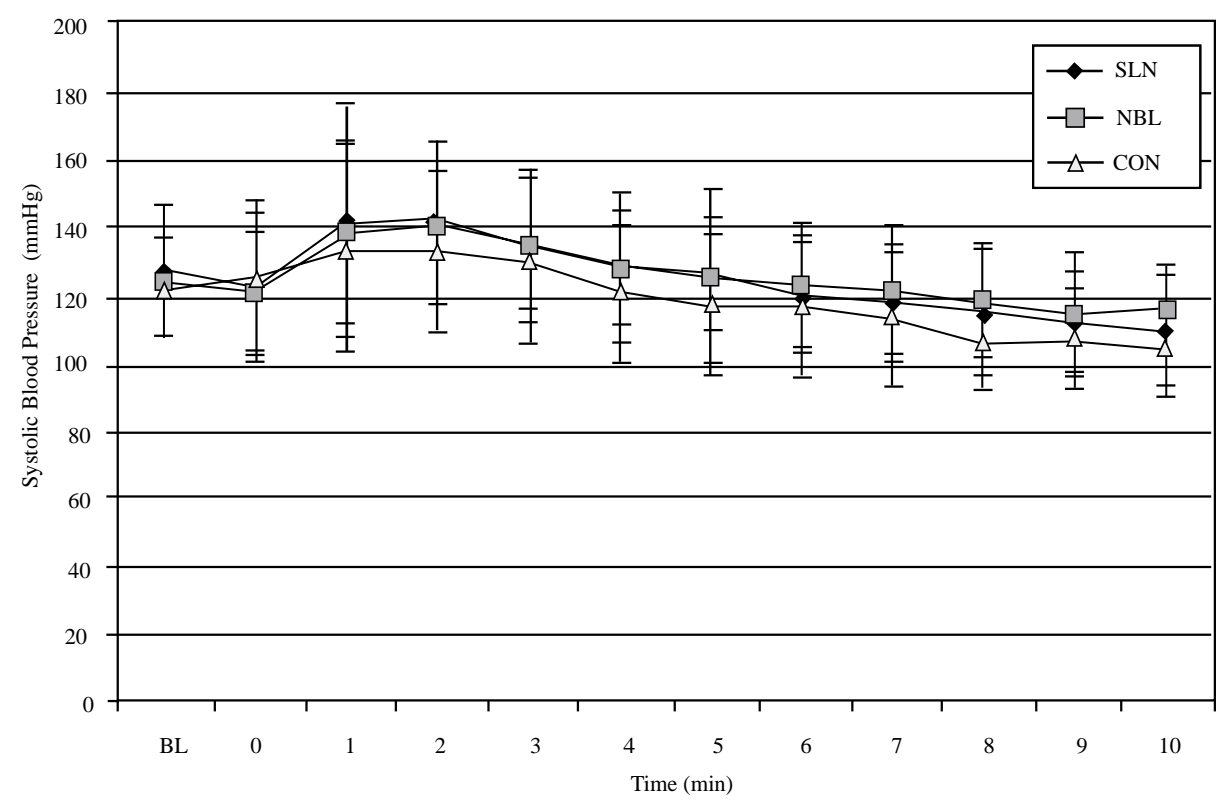

Fig. 2. Changes in systolic slood pressure over time.

Data points indicate group $\pm \mathrm{SD}$.

$B L=$ Baseline $; 0=$ Induction $; N=$ Minute $($ s) after intubation $; S L N=$ Superior laryngeal nerve block; $N B L=$ Nebulized lidocaine $; P L A=$ Placebo

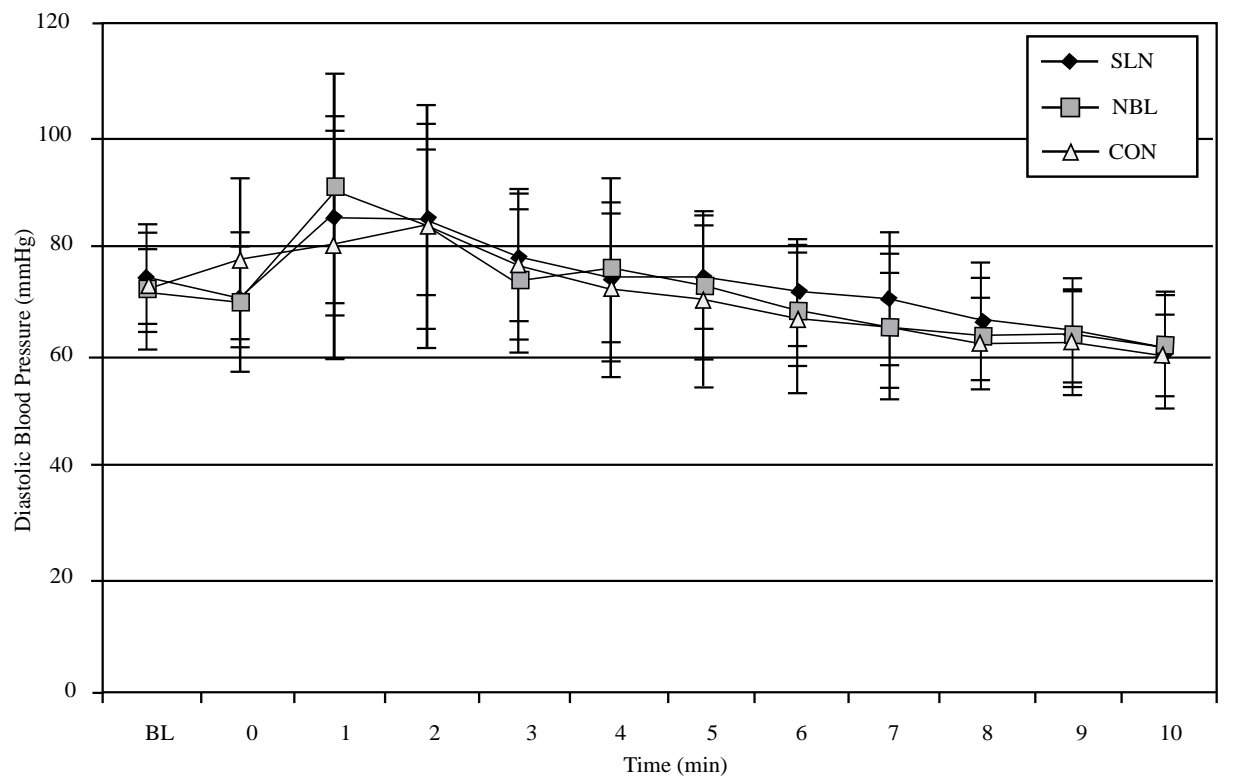

Fig. 3. Changes in diastolic blood pressure over time.

Data points indicate group $\pm \mathrm{SD}$.

$B L=$ Baseline $; 0=$ Induction $; N=$ Minute $($ s) after intubation $; S L N=$ Superior laryngeal nerve block; $N B L=$ Nebulized lidocaine $; P L A=$ Placebo 


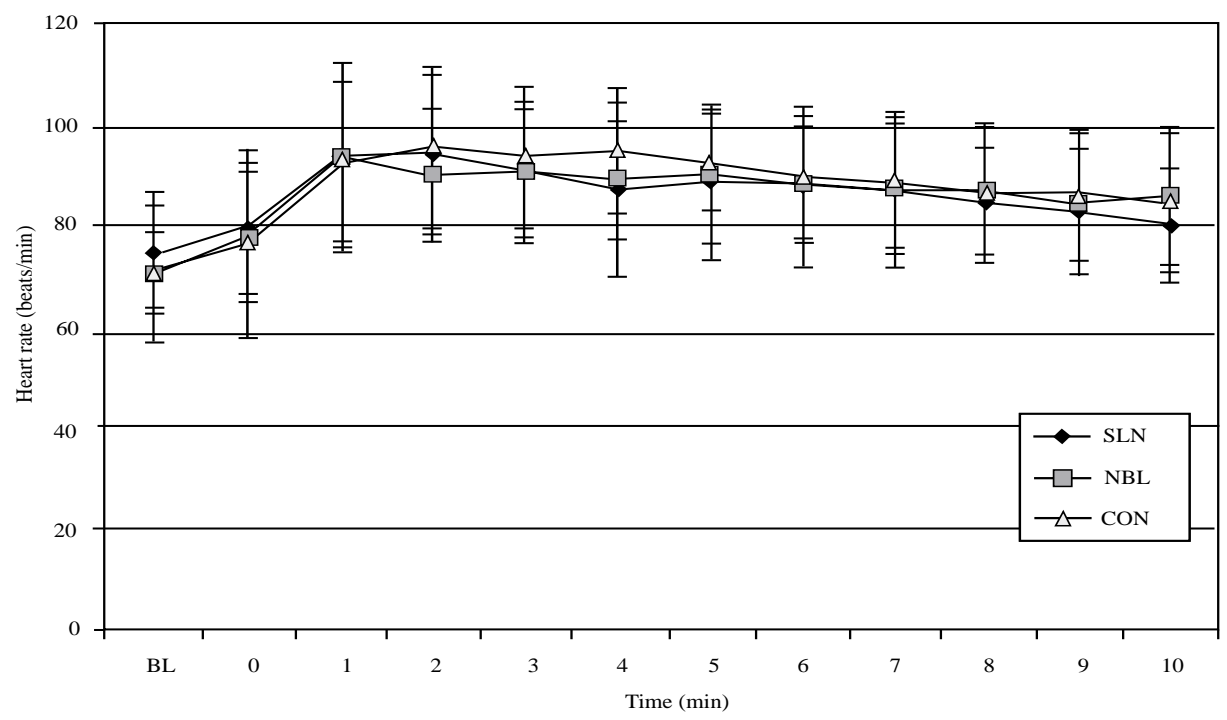

Fig. 4. Changes in heart rate over time. Data points indicate group $\pm \mathrm{SD}$.

$B L=$ Baseline $; 0=$ Induction $; N=$ Minute $(s)$ after intubation $; S L N=$ Superior laryngeal nerve block; $N B L=$ Nebulized lidocaine $; P L A=$ Placebo

\section{Discussions}

Tracheal intubation is associated with a haemodynamic response clinically characterized by increases in HR and blood pressure. These circulatory changes are thought to be somatovisceral reflexes that are triggered during laryngoscopy by stimulation of propriceptors at the base of the tongue ${ }^{[5]}$. We, therefore, hypothesized that anaesthetizing the upper airway would attenuate these reflexes and minimize the accompanying circulatory changes. The current investigation, however, demonstrated that upper airway anaesthesia with either nebulized lidocaine or bilateral superior laryngeal nerve block did not attenuate the hyperdynamic response to orotracheal intubation. Based on an $a$ of 0.05 , sigma of 10.32 , the study had a $76 \%$ chance of detecting a difference on 10 $\mathrm{mmHg}$ among the study groups had such a difference truly existed. On the other hand, given the observed group means, the study would have had to be extended to enroll 173 patients per group in order to achieve an $80 \%$ statistical power. This could not be justified and hence, the decision was to terminate the study.

The negative results of this trial were likely due to the fact that tracheal intubation could be viewed as a two-part process; laryngoscopy and intubation. Although the response to laryngoscopy might have been blunted by superior laryngeal nerves block and by nebulized lidocaine, the passage of the endotracheal tube through the vocal cords would still have evoked a sympathetic response. This could be attributed to the lack of airway anaesthesia below the vocal cords in SLN patients, and to inadequate an- 
aesthesia in NBL subjects. This view is supported by the findings of Asfar et al. who demonstrated lower blood pressure values, in response to tracheal intubation, in patients who received transtracheal lidocaine compared with those who received placebo [7]. The current investigation, however, was not designed to make this distinction in the intubation process, and further studies are needed to confirm this hypothesis.

Another plausible explanation for the negative results of this trial is inadequate anaesthesia of the upper airway. In group SLN, it was assumed that the nerve block was successful in the majority of patients based on the results of Stockwell et al. who performed superior laryngeal nerve block in 20 cadavers using methylene blue as a simulated local anaesthetic $^{[8]}$. Although Stockwell et al. reported a 97\%\% success rate based on the findings of heavily stained internal branch of the superior laryngeal nerve on dissection ${ }^{[8]}$, the success rate of the nerve block in this study remains unknown. As far as nebulized lidocaine is concerned, $2 \mathrm{mg} \mathrm{kg}^{-1}$ has been reported to be effective in attenuating the circulatory response to laryngoscopy and endotracheal intubation ${ }^{[9]}$. On the other hand, Laurito et al. failed to demonstrate a significant effect with a dose of 4 $\mathrm{mg} \mathrm{kg}^{-1}$ of aerosolization lidocaine ${ }^{[10]}$. Our results are in keeping with those of Laurito $^{[10]}$, however, lidocaine was administered in a fixed dose of $200 \mathrm{mg}$ in the current study. The most likely explanation for the observed discrepancy between our results and those of Laurito et al. ${ }^{[10]}$. in that much of the nebulized lidocaine in our study is lost to the air and in the patient's mouth. This is supported by the findings of Chinn et al. who demonstrated that up to $60 \%$ of the lidocaine dose can be lost via the nebulized route $^{[11]}$. In addition, Graham et al. reported that $4 \mathrm{ml}$ of $4 \%$ nebulized lidocaine provides inadequate anaesthesia for fibreoptic bronchoscopy ${ }^{[12]}$. It has also been suggested that nebulized lidocaine may partially inhibit the vagus afferents ${ }^{[13]}$. This by itself may result in unopposed sympathetic outflow with consequent increases in HR and BP that are accentuated by laryngoscopy and intubation. Although this hypothesis could explain the persistence of tachycardia in the other study groups. It is, however, possible that the persistence of increase heart rate throughout the study period was due to light anaesthesia, which in turn contributed to the observed negative results in this study.

Limitations of the current study include the inability to confirm the success of superior laryngeal nerves block, lack of adequate anaesthesia below the vocal cords, and the possibility of light anaesthesia in view of the absence of narcotics among the induction drugs. Also, the use of isoflurane for maintenance of anaesthesia could have contributed to the observed tachycardia and hypertension especially with the abrupt increase in the alveolar concentration of isoflurane ${ }^{[14]}$. Although the duration of laryngoscopy was neither controlled nor recorded, all tracheal intubations were performed without any difficulties. Finally the possibility of a type II error could not be ruled out because of the relatively low power of the study.

In conclusion, the results of this study suggest that upper airway anaesthesia with either bilateral superior laryngeal nerve block or nebulized lidocaine may not be sufficient by itself to ameliorate the hyperdynamic response to tracheal intubation. The 
importance of these findings is the apparent need for intravenous drugs to control the hyperdynamic response to upper airway instrumentation particularly in those who may not tolerate the haemodynamic response to tracheal intubation.

\section{Acknowledgement}

The author is grateful to Dr. Majid Y. Jubili, MD, MSc, for his help in the Arabic translation. The cooperation of anaesthesia colleagues is also acknowledged.

\section{References}

[1] Prys-Roberts C, Greene LT, Meloche R, Foex P. Studies of anaesthesia in relation to hypertension. II. Haemodynamic consequences of induction and endotracheal intubation. Br J Anaesth 1971; 43: 531-547.

[2] Singh H, Vichitvijpaisal P, Gaines GY, White PF. Comparative effects of lidocaine, esmolol, and nitroglycerin in modifying the haemodynamic response to laryngoscopy and intubation. $J$ Clin Anesth 1995; 7: 5-8.

[3] Weiss-Bloom LJ, Reich DL. Haemodynamic responses to tracheal intubation following etomidate and fentanyl for anaesthetic induction. Can J Anaesth 1992; 39: 780-785.

[4] Mikawa K, Ikegaki J, Maekawa N, Goto R, Kaetsu H, Obara H. The effect of diltiazem on the cardiovascular response to tracheal intubation. Anaesthesia 1990; 45: 289-293.

[5] Hassan HG, el-Sharkawy TY, Renck H, Mansour G, Fouda A. Haemodynamic and catecholamine responses to laryngoscopy with vs. without endotracheal intubation. Acta Anaesthesiol Scand 1991; 35: $442-447$.

[6] Murphy TM. Somatic blockade of head and neck. In: Cousins MJ. Bridenbaugh PO, eds. Nureal Blockade in Clinical Anaesthesia and Management of Pain. Philadelphia: Lippincott-Raven Publishers, 1998: 504.

[7] Asfar SN, Abdulla WY. The effect of various administration routes of lidocaine on haemodynamics and ECG rhythm during endotracheal intubation. Acta Anaesthesiol Belg 1990; 41: 17-24.

[8] Stockwell M, Lozanoff S, Lang SA, Nyssen J. Superior laryngeal nerve block: an anatomical study. Medicine Caliban Manuscripta Geo 1995; 8: 89-95.

[9] Sklar BZ, Lurie S, Ezri T, Krichelli D, Savir I, Soroker D. Lidocaine inhalation attenuates the circulatory response to laryngoscopy and endotracheal intubation. J Clin Anesth 1992; 4: 382-385.

[10] Laurito CE, Baughman VL, Becker GL, Polek WV, Riegler FX, VadeBoncouer TR. Effects of aerosolized and/or intravenous lidocaine on hemodynamic responses to laryngoscopy and intubation in outpatients. Anesth Analg 1988; 67: 389-392.

[11] Chinn WM, Zavala DC, Ambre J. Plasma levels of lidocaine following nebulized aerosol administration. Chest 1977; 71: 346-348.

[12] Graham DR, Hay JG, Clague J, Nisar M, Earis JE. Comparison of three different methods used to achieve local anaesthesia for fibreoptic bronchoscopy. Chest 1992; 102: 704-707.

[13] Mador MJ. Effect of nebulized lidocaine on ventilatory response to CO2 in health subjects. J Appl Physiol 1993; 74: 1419-1424.

[14] Yli-Hankala A, Randell T, Seppala T, Lindgren L. Increases in hemodynamic variables and catecholamine levels after rapid increase in isoflurane concentration. Anesthesiology 1993; 78: 266-271. 


\title{
تأثير تخدير مجرى الهو اء العلوي على الاستجابة الدينامكية المفرطة المر افقة للتنبيب الرغامي
}

\author{
جمال آل حاشيمي \\ قسم التخدير ، كلية الطب والعلوم الطبية \\ جامعة الملك عبدالعزيز \\ جـــــة - المملكة العربية السعودية
}

المستخلص. يتر افق التنبيب الرغامي مع استخجابة دينامكية دورانية

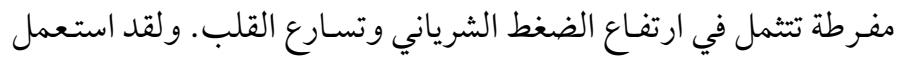

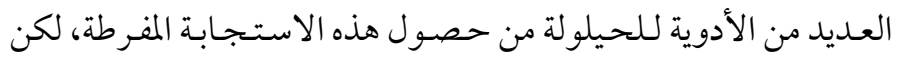

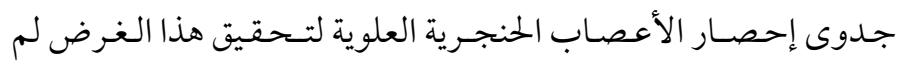

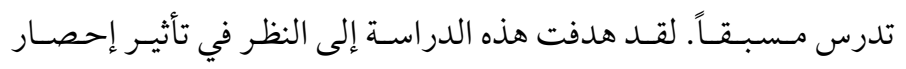

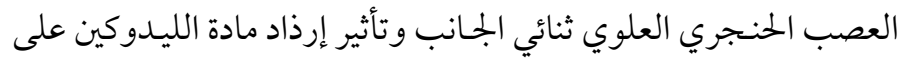

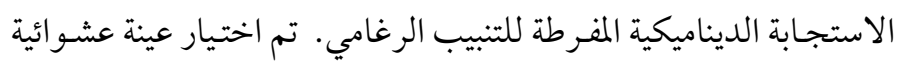

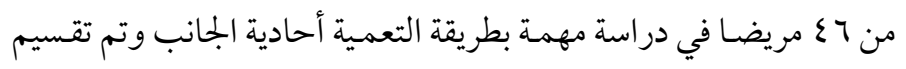

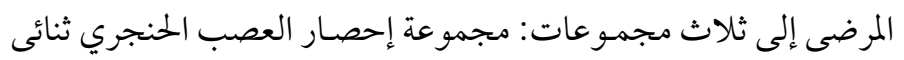

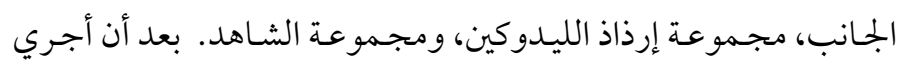

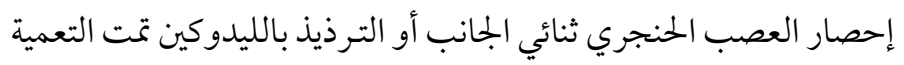

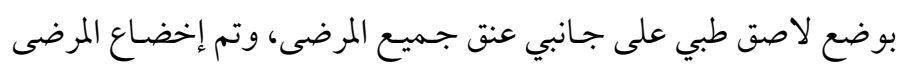

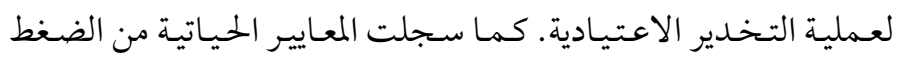

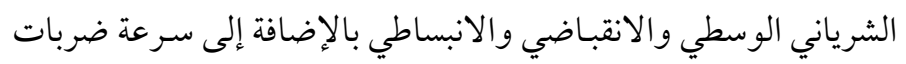

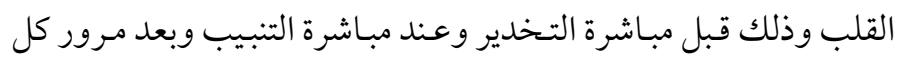

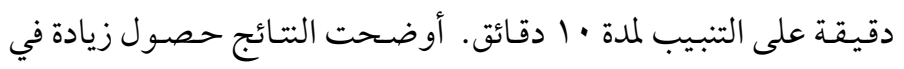

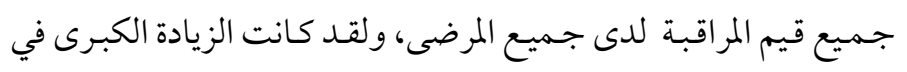

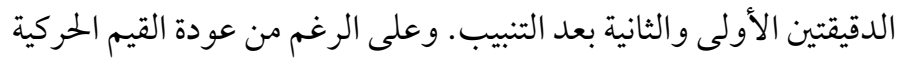

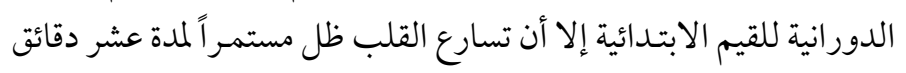




$$
\text { بعد التنبيب الرغامي. }
$$

يستخلص من هذه الدراسة إلى أن إحصار العصب الحنجري العلوي

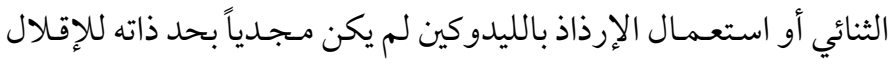
من الاستجابة الدينامكية الدورانية المفرطة المترافقة مع التنبيب الرغامي. 